\title{
NOVOS ENUNCIADORES DA PUBLICIDADE: PERFIS FICTÍCIOS NO BRANDED CONTENT DA CERVEJA ANTARCTICA
}

\author{
New advertising emitters: fictional profiles in Antarctica \\ beer's branded content
}
Nuevos emisores de la publicidad: perfiles ficticios en el branded content de la cerveza Antarctica

\author{
Sandro Tôrres de Azevedo \\ Faculdades Integradas Hélio Alonso, Rio de Janeiro, Brasil. \\ Publicitário, pesquisador e professor no ensino superior desde 1999. Doutor em Estudos de Linguagem \\ pela Universidade Federal Fluminense (UFF). Mestre em Comunicação e Cultura pela Universidade Federal \\ do Rio de Janeiro. Graduado em Comunicação Social com habilitação em Publicidade e Propaganda pela \\ UFF. Vice-líder do ReC - Grupo de Pesquisa em Retórica do Consumo (UFF/CNPq). Membro do SeDi - \\ Grupo de Pesquisa em Semiótica e Discurso (UFF/CNPq). Trabalha academicamente com objetos da \\ comunicação social, tendo ministrado disciplinas dessa área em nível de graduação e pós-graduação (lato \\ sensu) nas seguintes instituições: Faculdades Integradas Hélio Alonso, Universidade Veiga de Almeida \\ Universidade Estácio de Sá, Escola Superior de Propaganda e Marketing e Instituto Infnet. \\ E-mail: sandrotorres.com@gmail.com
}

\section{Daniele de Castro Alves}

Universidade Estadual do Rio de Janeiro, Rio de Janeiro, Brasil Doutoranda e mestre em Comunicação pelo PPG em Comunicação da Universidade Estadual do Rio de Janeiro. Possui graduação em Comunicação Social, habilitação em Publicidade e Propaganda pela Universidade Federal do Rio de Janeiro e MBA em Marketing Estratégico pela Univercidade. Desde 1994, atua como redatora publicitária nas áreas de propaganda, merchandising, ponto de venda, endomarketing/comunicação interna, marketing direto e branding. Presta também consultoria em planejamento estratégico e branding. Estudos e pesquisas com ênfase em tecnologias da comunicação, ciberpublicidade, comunicação e consumo, branded content e narrativa publicitária. E-mail: danieledecastroalves@gmail.com

\section{Mariana Ayres Tavares Vasconcelos}

Centre d’Études Luttéraires et Scientifiques Appliquées Paris-Sorbonne, Paris, França. Doutoranda na Université Paris-Sorbonne (École Doctorale V - Concepts et Langages). Possui mestrado pelo PPG em Comunicação Social da Pontifícia Universidade Católica do Rio de Janeiro, especialização em Pesquisa de Mercado e Opinião Pública na Universidade do Estado do Rio de Janeiro, graduação em Comunicação Social com habilitação em Publicidade pela Universidade Federal Fluminense. Tem experiência na área de comunicação, com ênfase em publicidade, pesquisa de mercado e inovação nas empresas Oi e L'Oréal Brasil.

E-mail: ayres.mari@gmail.com

RESUMO Neste trabalho, analisamos as interações estabelecidas na página do perfil fictício Marcelão da BOA, personagem do conjunto de webséries "Coisa boa gera coisa boa", promovido pela marca de cerveja Antarctica como parte integrante de sua corrente ação de branded content. Para tanto, recuperamos conceitos afeitos à relação 
entre ciberpublicidade e prossumidores, bem como revisamos algumas perspectivas sobre o branded content. Assim, procuramos investigar as trocas discursivas entre marca e consumidores sob o prisma dos regimes de interação dados pelo ferramental teórico da sociossemiótica.

PALAVRAS-CHAVE Perfis fictícios, Branded content, Publicidade, Semiótica, Cerveja Antarctica.

ABSTRACT In this work, we analyze the interactions established in the fictional profile page Marcelão da BOA, a character from the set of web series "Coisa boa gera coisa boa", promoted by the Antarctica beer brand as an integral part of its current branded content action. To do so, we recover concepts related to the relationship between cyber advertising and prosumers, as well as review some perspectives on branded content. Thus, we seek to investigate the discursive exchanges between brand and consumers under the prism of the interaction regimes given by the theoretical tool of socio-semiotics.

KEYWORDS Fictional profiles, Branded content, Advertising, Semiotics, Antarctica beer.

RESUMEN En este trabajo, analizamos las interacciones establecidas en la página del perfil ficticio Marcelão da BOA, personaje del conjunto de series web "Coisa boa gera coisa boa", promovido por la marca de cerveza Antarctica como parte integrante de su acción de branded content. Para ello, recuperamos conceptos referentes con la relación entre ciberpublicidad y prosumidores, así como revisamos algunas perspectivas sobre el branded content. De este modo, buscamos investigar los intercambios discursivos entre marca y consumidores bajo el prisma de los regímenes de interacción dados por el instrumento teórico de la socio semiótica.

PALABRAS CLAVE Perfiles ficticios, Branded content, Publicidad, Semiótica, Cerveza Antarctica.

\section{INTRODUÇÃO}

Neste trabalho, propomo-nos a refletir sobre a interação estabelecida entre marcas e consumidores através de um novo recurso técnico e estratégico explorado pela publicidade contemporânea: páginas de perfis fictícios em mídias sociais digitais. Especificamente, tomamos o caso da página do perfil do Marcelão da BOA no Facebook, parte integrante da ação de branded content da cerveja Antarctica intitulada "Coisa boa gera coisa boa”, como objeto de análise. Em nossa investida, adotamos o método indutivo, que evolui do particular para o geral, com a finalidade de desvelar aspectos genuinamente novos da relação comunicativa travada entre marcas e consumidores na atualidade.

O percurso da nossa abordagem inicia-se com um breve resgate da ciberpublicidade e sua inerente e profunda relação com os prossumidores, atravessamos conceitos sobre o branded content, tomando-o como tendência da corrente comunicação publicitária, para chegarmos ao nosso estudo de caso. Depois disso, procuramos diferenciar o perfil fictício e sua potência comunicativa da publicidade testemunhal ordinária, até que desembocamos na articulação entre as teorias sobre os regimes de interação, dadas pela sociossemiótica, e as trocas de sentido estabelecidas através das postagens realizadas na página do Marcelão da BOA.

\section{CIBERPUBLICIDADE E PROSSUMIDOR}

O advento das novas tecnologias da informação e da comunicação contribuem para engendrar profundas mudanças socioculturais e 
novos hábitos de consumo, propiciando diversas modificações no cenário midiático, marcado pela ruptura do modelo de comunicação unidirecional das mídias de massa. As propriedades implementadas pela Web 2.0, que permitem a participação mais ativa do usuário, colaboram para reconfigurar a criação de conteúdo e o uso da internet. Essas transformações colaboram para alterar o modo de consumir os meios e a interação com o conteúdo, disperso em múltiplos suportes na narrativa transmidiática (JENKINS, 2009). A liberação do polo emissor na comunicação e o comportamento migratório do consumidor entre meios online e off-line também demandam uma certa reconfiguração do fazer publicitário, originando a ciberpublicidade, calcada pela tríade "interatividade-relevância-experiência" (ATEM; OLIVEIRA; AZEVEDO, 2014, p. 10). Com a atuação mais ativa do prossumidor, que pode criar e ressignificar conteúdos, a ciberpublicidade busca engajar o público, convocando o consumidor a ser coenunciador, em um constante diálogo para construir conjuntamente a narrativa da marca.

Em sintonia com essas mudanças, a união entre as indústrias da publicidade e do entretenimento se consolida como forma estratégica para conquistar a atenção da audiência: "para isso é necessária uma mudança total de mentalidade, de um modelo baseado na intrusão a um modelo estruturado no convite e na sedução do consumidor" (DONATON, 2007, p. 21).

Os desafios enfrentados pela publicidade são agravados com a lógica on demand da cultura digital, na qual novos hábitos de consumo alteram o modo interruptivo da publicidade, que nas mídias digitais pode ser facilmente suprimida, como mensagens no pre-roll de vídeos no YouTube, ou até mesmo não existir, como no modelo de negócios da Netflix. Além disso, o público tem adotado como prática a utilização de recursos para bloquear a publicidade nos meios digitais, como firewalls, ads cleaners e também ad blockers nas versões de aplicativos para dispositivos móveis e de extensões para navegadores na internet.

Nesse cenário, permeado por diversas transformações, emergem as práticas de branded content, que, ao mesclarem publicidade e entretenimento, possibilitam uma abordagem estratégica para oferecer conteúdo relevante e estreitar o relacionamento entre marcas e prossumidores.

\section{O BRANDED CONTENT COMO TENDÊNCIA PUBLICITÁRIA}

De um modo geral, o branded content torna tênues as fronteiras entre informação, publicidade e entretenimento para oferecer experiências positivas e gerar vínculos emocionais entre as marcas e seus consumidores. Como diferencial em relação à publicidade tradicional, veiculada nos meios de comunicação de massa e facilmente identificada pela audiência, o branded content dispensa o apelo à venda e procura não interromper a experiência do público.

Como o branded content pode ser considerado um fenômeno relativamente recente, as práticas englobam diferentes formatos, características e conceituações, uma pluralidade que salienta a necessidade de realizar investigações acadêmicas e mercadológicas para aprofundar a compreensão sobre o tema.

Com as práticas de branded content, o conteúdo pode ser melhor recebido pelo público, reduzindo a resistência ao modelo de publicidade convencional, que, de um modo geral, interrompe o entretenimento com os intervalos comerciais nos meios de comunicação de massa (COVALESKI, 2013). 
Covaleski (2015) destaca que uma das principais características do branded content é não apresentar o apelo da venda direta e concentrar esforços para construir uma personalidade para a marca, que pode até ser inserida na narrativa do entretenimento, de modo relevante, reforçando o seu posicionamento diante do consumidor.

Martí-Parreño, Ruiz-Mafé e Scribner (2015) tratam diversas questões referentes à hibridização entre publicidade e entretenimento, no livro Engaging Consumers through Branded Entertainment ${ }^{1}$ and Convergent Media, uma nova abordagem na comunicação mercadológica que beneficia tanto publicitários quanto consumidores:

Branded entertainment é a inserção da marca em uma propriedade de entretenimento de modo que a linha entre entretenimento e publicidade se torna tênue. Ao borrar as fronteiras entre conteúdo publicitário e conteúdo editorial, o branded entertainment está ganhando força como estratégia de comunicação mercadológica, oferecendo, tanto aos publicitários quanto aos consumidores, conteúdo de marca altamente envolvente que os beneficia de forma sinérgica. Por um lado, os consumidores podem acessar conteúdo gratuito, como filmes on-line, jogos (advergames), livros, quadrinhos ou música desenvolvidos pelas marcas. Por outro lado, os publicitários podem alcançar audiências engajadas que estão buscando entretenimento e atingi-las com mensagens da marca de um modo menos intrusivo no contexto da publicidade. (Ibidem, p. XVI, tradução nossa)

Assim é que os pesquisadores vão além e sintetizam: "branded entertainment é qualquer conteúdo de entretenimento (ex.: filmes, vídeo games, livros) desenvolvido por uma marca - e geralmente em torno da marca - para atingir seus objetivos de marketing” (Ibidem, p. 4, tradução nossa).

A partir do exposto, é possível constatar como o branded content desempenha um papel expressivo na comunicação mercadológica contemporânea, uma abordagem que conquista cada vez mais investimentos das marcas e suscita uma série de novas práticas.

\section{COISA BOA GERA COISA BOA: BRANDED CONTENT DA ANTARCTICA}

Se o branded content é uma tendência mundial, um bom exemplo no Brasil é a ação "Coisa boa gera coisa boa”, que vem sendo desenvolvida pela marca de cerveja Antarctica desde 2016 com webséries (sete temporadas até o momento) $)^{2}$. O projeto engloba uma gama de produtos midiáticos veiculados em diversas plataformas, especialmente nos canais de comunicação da marca (site e páginas institucionais em Facebook, Instagram, YouTube e Spotify).

A série contempla um universo narrativo com situações de drama/ comédia apresentando personagens que associam a ideia do carioca ao espírito da marca: paixão pelo samba e cerveja, solidariedade, autenticidade e leveza para lidar com adversidades do cotidiano.

1. Os autores explicitam no livro que as expressões branded entertainment, preferida na academia, e branded content, denominação que prevalece no mercado, são usadas como sinônimos.

2. Ver: http://www.antarctica.com.br/campanhas. 
A primeira temporada, \#NoGogó, inicia todo o arco narrativo do branded content ao contar a história de Guto (Thiago Martins), um morador de comunidade que sonha em ser cantor, é vendedor ambulante de cerveja nas praias do Rio de Janeiro e que se apaixona por Duda (Eline Porto), moradora do Leblon, área nobre da cidade.

A escolha de Thiago Martins para viver o protagonista da websérie contribui para reforçar a imbricação da narrativa com a realidade, já que o ator foi morador do Vidigal, favela vizinha ao bairro do Leblon, vendedor na praia e cantor. O personagem contava com uma página no Facebook com o nome "Guto da BOA" e a forma de interação proposta pela marca era a de um diálogo pessoal.

Após as cinco primeiras temporadas da websérie, em dezembro de 2017 houve uma transição da página do "Guto da BOA"3 para a do "Marcelão da BOA"4, interpretado pelo ator Rafael Portugal (Figura 1). Todo o conteúdo gerado pelo Guto continuou disponível na página do Marcelão, já que houve uma "passagem oficial" da administração da página de um personagem para o outro. Marcelão apresenta uma personalidade mais voltada ao humor, que, mesmo com seu jeito atrapalhado, adquire papel central na série, conduzindo o mote da marca, "coisa boa gera coisa boa".
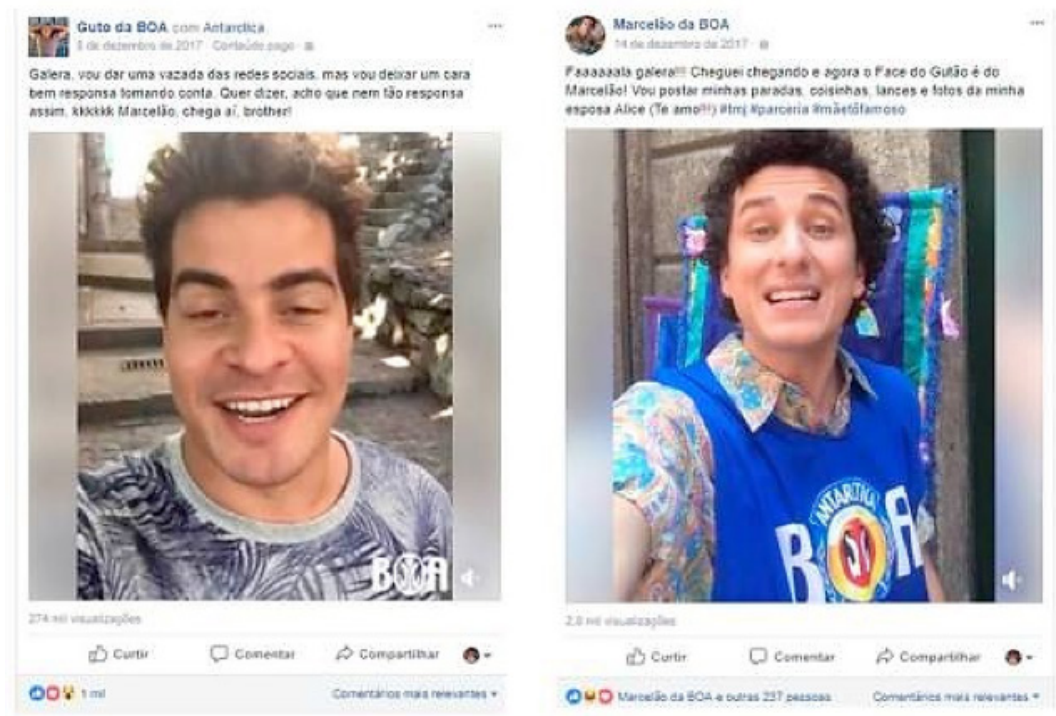

Figura 1. Transição dos perfis entre os personagens.

Fonte: Facebook (Páginas Guto da BOA e MarcelaoBOA, dez. 2017).

Após a mudança, a marca lançou duas novas webséries, que, além do Marcelão, apresenta mais um personagem, o Mauro, interpretado pelo ator Eduardo Sterblitch. Com essa nova fase, protagonizada por Marcelão, a página do Facebook não apresenta mais postagens para endossar a confusão entre ficção e realidade, um indício que, de certa forma, após usar bastante esse recurso anteriormente, o público já se acostumou com o perfil fictício do personagem, o que pode ser percebido pelas interações nos comentários, em que há menções ao nome do personagem e ao do ator, Rafael Portugal.

3. URL original (indisponível): https://www.facebook.com/GutoBOA.

4. URL original (indisponível): https://www.facebook.com/MarcelaoBOA. 


\section{PERFIS FICTÍCIOS VERSUS TESTEMUNHAIS}

Em alguma medida, poderíamos atribuir ao perfil fictício semelhante função dada ao "garoto propaganda" de uma marca que age como instância testemunhal. Todavia, ao longo de nossos estudos, identificamos aspectos que os distanciam e tornam impossível tal comparação.

Há muito a publicidade usa famosos ou especialistas para que suas qualidades sejam estendidas ou conferidas ao objeto do anúncio. No caso do especialista, a ideia é atribuir credibilidade à mensagem, dado que ele age como uma autoridade que chancela o uso ou atesta as vantagens daquilo que se anuncia. Ocorre, por exemplo, com o dentista que recomenda o creme dental ou o economista que sugere alguma aplicação específica de um banco.

Em relação à celebridade, a imagem da pessoa notável é diretamente associada à identidade da marca, que busca personalidades ilustres do cinema, da TV, dos esportes etc., de modo que personifiquem o posicionamento pretendido, realizando, assim, um processo de transferência de valores. E o sucesso desse mecanismo se dá no momento em que o público consumidor projeta para si os valores que reconhece na celebridade (beleza, requinte, exclusividade etc.), tomando a marca anunciante endossada como elemento viabilizador dessa conexão.

O uso de celebridades é uma constante na publicidade, principalmente pela sua capacidade mobilizadora de audiência e incremento do índice de lembrança da mensagem da marca.

Celebridades têm essa capacidade de parar o "dedo nervoso" do consumidor sobre o controle remoto, mas se não conseguir surpreender o espectador, se disser o óbvio, o esperado, a atenção do observador se desfará e o zapping recomeçará. (FIGUEIREDO, 2005, p. 118)

Contudo, essa eficiência mobilizadora é observada num contexto de mídia passiva de massa. Na circunstância interativa apresentada pelas mídias conectadas, a publicidade normalmente explora o potencial da celebridade para "emulação de autenticidade e proximidade enquanto provoca o desejo dos fãs” (PRIMO, 2009, p. 4). Nesses casos, a exposição da vida privada da pessoa famosa é o ponto alto do que realmente chama a atenção dos consumidores. O regime de total visibilidade da figura midiática desloca o propósito de projeção outrora explorado nos testemunhais publicitários para uma situação de identificação, no qual o consumidor aproxima de si o modo de vida exibido pelo famoso, por mais singular ou extravagante que possa parecer.

Observando o objeto de análise deste trabalho, não podemos confundir o perfil fictício do Marcelão da BOA com o de um simples garoto-propaganda ou mesmo imaginar o Rafael Portugal como um ator que transfere atributos da sua imagem para a Antarctica; todas essas afirmações reduzem o fenômeno estudado a antigas práticas, que limitariam o jogo publicitário à produção e emissão de conteúdos unidirecionais, deixando de lado as interações travadas nos espaços de conexão dialógica próprios da atual Web 2.0 explorados pela marca.

No campo das interações, não é a imagem do ator que é percebida como a identidade da marca, mas sim a do personagem fictício, que possui uma narrativa construída através da websérie e de todo complexo sistema comunicativo desenvolvido em torno dela. De outra forma, todos os atributos que a marca deseja imprimir são construídos por ela mesma através do perfil fictício. 
Isso pode ser verificado fazendo uma simples análise de algumas postagens e constatando a baixa incidência de referências ao ator. Por exemplo, num post na página do Marcelão da BOA em 29 de março de 2018, foram feitos 272 comentários, dentre os quais apenas quatro faziam referência ao Rafael Portugal, enquanto mais de trinta se referiam diretamente ao Marcelão e mais de uma centena se dirigiam ao personagem independentemente de vocativo, mas em clara alusão ao sujeito ficcional ("bom dia”, "boa noite”, "parabéns”, "saudades”). Em alguns casos fica evidente a confusão entre o tipo fictício e o intérprete, mas, no todo, é flagrante o envolvimento dos interagentes com o sujeito enunciado pela campanha, revelando uma relação inclusive afetiva, o que nos leva a crer que o Marcelão age pela humanização da marca.

Dessa maneira, podemos afirmar que é justamente a interação o fator desencadeador das relevantes distinções entre o já consolidado modelo de publicidade testemunhal e essa nova tática que se vale de personagens fictícios em ambientes virtuais de comunicação multidirecional.

\section{PERFIS FICTÍCIOS E INTERAÇÕES ARRISCADAS}

Para analisar as interações estabelecidas entre consumidores e o perfil fictício da ação de branded content da Antarctica, recorremos à semiótica discursiva, em especial à sociossemiótica de Eric Landowski o autor justamente reivindica o ferramental teórico da semiótica como instrumento conexo à comunicação na especificidade das análises de interações (LANDOWSKI, 2016). Por isso, parece-nos rendoso usar os conceitos sobre os regimes de interação para observar os fenômenos comunicativos que ocorrem na área dos comentários da página do perfil para daí refletirmos sobre estatutos que regem as dinâmicas da interação na ciberpublicidade.

Na obra Interacciones Arriesgadas, Landowski (2009) teoriza sobre as formas do indivíduo construir relações com o mundo que habita, com o outro e consigo mesmo. Dessa maneira, considera que, nas atividades comunicativas inerentes às práticas sociais, se articulam quatro tipos de regimes de interação: programação, manipulação, ajustamento e acidente.

As interações em regime de programação ocorrem em circunstâncias nas quais os contatos com os sujeitos-sujeitos ou os sujeitos-objetos se dão de forma que já implicam na operação de um fazer-ser, tomando o indivíduo ou objeto com o qual se interage por "programado", isto é, remetendo à ideia de um "algoritmo de comportamento" (Ibidem, p. 20), do qual não se pode escapar. Há uma expectativa razoavelmente segura sobre as reações possíveis, um coeficiente de previsibilidade, e, por isso, nesses casos, a interação envolve um risco mínimo por parte do indivíduo operador, que se vale das regularidades dos comportamentos adotadas pelos atores possíveis, predeterminadas pela função básica das coisas, dadas pela causalidade física (quando se trata de operar objetos), ou pelos estereótipos da vida sociocultural, derivados das coerções sociais (quando a operação incide sobre pessoas).

O regime de manipulação (Ibidem, p. 23), por seu turno, envolve interações as quais revelam intenções que se colocam para além de um fazer-ser, dirigindo-se para um fazer-fazer. 0 regime implica um princípio de intencionalidade manifesto em estratégias que tratam dos sujeitos narrativos (o manipulador e o manipulado) e que os estudos semióticos já abordaram em abundância. A manipulação difere da programação principalmente porque o sujeito manipulador em 
potência atribui ao seu coparticipante um estatuto semiótico idêntico ao que reconhece em si mesmo, ou seja, também vê o outro como um sujeito (Ibidem, p. 25). Naturalmente, esse regime de interação considera as competências modais exercidas pelos sujeitos nos eixos temáticos possíveis, aumentando o risco, mesmo que pouco, dado que a manipulação se manifesta através da eleição de estratégias que cingem o interlocutor às competências construídas pelo manipulador que, enfim, razoavelmente limita-as a um prognóstico afeito ao propósito do fazerfazer intencionado.

Na sequência, Landowski (Ibidem, p. 45) propõe um regime que denominou de ajustamento. Nesse caso, a gestão das relações entre os atores se amplia consideravelmente em termos de criação de sentido, revelando um aspecto "intuitivo" que é frequente nos processos relacionais do cotidiano, sobre o qual as teorias semióticas sobre a programação e a manipulação haviam se mostrado insuficientes. As interações em regime de ajustamento, então, são aquelas que trabalham com competências mais "abertas”, que inspiram um fazersentir, ou seja, para além da dissuasão, considerando, portanto, uma lógica do contato e implica uma problemática da "união" (Ibidem, p. 48). Dessa maneira, há de se considerar os sujeitos interlocutores como iguais, sendo cada parte responsável por coordenar as dinâmicas estabelecidas através de um fazer conjunto. Se a programação se resumia ao exercício de energias e "forças cegas” por sobre o outro, já que não se reconhecia nada que não fossem constantes, e a manipulação, por sua vez, apesar de reconhecer o outro como um sujeito modalizado, dotado de inteligência e autonomia, se concentrava apenas na persuasão, agora, no ajuste, os sujeitos se equivalem, o que revela uma situação em que há trocas entre "corpos sencientes e corpos sentidos” (Ibidem, p. 49), próprias das experiências vividas no dia a dia. Daí, Landowski marca a "liberação" que o regime de ajustamento dá às interações possíveis, pois que amplia sobremaneira as possibilidades de emergência de sentidos, dado que a imprevisibilidade é o que governaria a interação, eliminando, a antevisão planificada por esse ou aquele sujeito da interlocução. Enfim, não há como não perceber, o risco se amplia com mais intensidade quando se dá o regime de ajustamento, porquanto se instauram negociações inesperadas.

O último regime de interação analisado por Landowski é o do acidente. Essa interação se caracterizaria pela descontinuidade total diante das constantes, das coerções possíveis ou mesmo da ordem estabelecida. $\mathrm{O}$ regime do acidente está intimamente ligado à intranquilidade, à instabilidade, à agitação e ao caos e, por isso, perturba todas as noções ligadas aos regimes tratados anteriormente. É o escape ao sistema, mas não poderia, apesar disso, ser "depreciado" (Ibidem, p. 72). O absurdo ou o azar constituiria o princípio fundador desse regime de interação. 0 acidente desdobra entre o sensível e o aleatório, estando inexoravelmente descomprometido com alguma classe de regularidade causal ou por qualquer constante de ordem simbólica. Obviamente, enfim, o risco no acidente é elevado a patamares claramente muito superiores aos evidenciados nos outros regimes de interação.

É nítida a gradação do risco inscrito nas formas de interação propostas por Landowski: da programação para a manipulação, daí para o ajustamento e enfim para o acidente, vê-se o controle sobre a interação se rarefazer e, por fim, estabelecer uma hierarquia topológica francamente pertinente às análises semióticas que envolvem as cenas/textos para as quais a teoria tem se dirigido atualmente. 


\section{INTERAÇÕES COM PERFIS FICTÍCIO}

Tomando a mesma postagem aludida mais acima (Figura 2), para efeito de exame, é fácil deduzir que a marca enunciadora (Antarctica) considerou os recursos da programação algorítmica do Facebook para alcançar o seu público-alvo presente na mídia social. O enunciado é caracterizado pela indicação de "conteúdo pago" (assinalado no cabeçalho da postagem), o que sugere que foram aplicadas táticas de gestão de mídias sociais comuns ao uso técnico das ferramentas disponibilizadas pela plataforma do Facebook, relacionadas com os filtros de alcance das postagens.

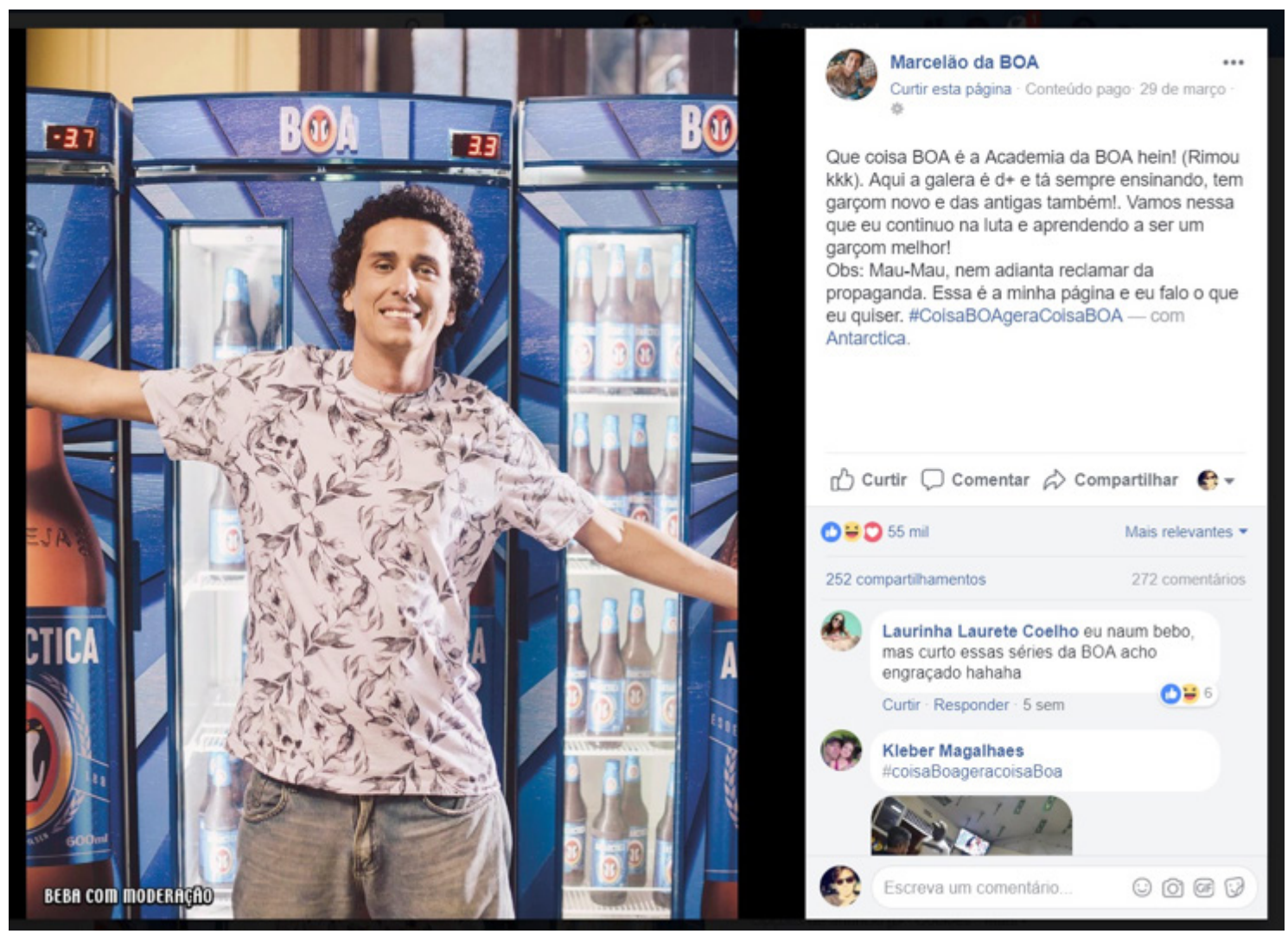

Figura 2. Exemplo de postagem na página do Marcelão da BOA Fonte: Facebook (Página MarcelaoBOA, mar. 2018).

Tal circunstância revela que a marca "abre um diálogo” com relativa segurança de que haverá um índice de respostas bastante considerável, pois presumivelmente impulsionou a postagem para alcançar um quantitativo elevado de pessoas, sendo que mesmo um percentual mínimo de retorno no amplo universo da cobertura planificada produz um resultado significativo em números absolutos. Isso se verifica no cômputo das "reações" (curtidas), na ordem de 55 mil até o momento.

Dessa maneira, a simples reação à postagem - até pelas poucas variações possíveis (representadas por seis tipos de "emojis"5) somadas a um trivial clique, feito muitas vezes de forma automatizada, como é

5. “Emojis são ideogramas e smileys usados em mensagens eletrônicas e páginas web [...]. Eles existem em diversos gêneros, incluindo: expressões faciais, objetos, lugares, animais e tipos de clima”. (EMOJI, 2018, on-line). 
muito comum nas navegações ordinárias na internet -, pode ser tomada como um tipo de interação em regime de programação. Com esse tipo de contato, dado o total de pessoas atingidas (de acordo com as informações disponibilizadas pela plataforma e que se traduzem em parte das métricas a serem observadas), a Antarctica afere a parcela que foi sensibilizada pela mensagem, mas não o suficiente para emitir um retorno mais elaborado.

O mesmo pode se atribuir aos compartilhamentos. Apesar de multiplicar a mensagem da marca para além do seu alcance previamente programado e de usar os espaços do próprio público para repercuti-la (o que é obviamente interessante em termos de cobertura e autenticidade da publicidade), 0 compartilhamento indica pouquíssimo comprometimento dialógico.

É bem verdade que o compartilhamento em mídias sociais, em geral, especialmente no Facebook, dá a possibilidade de o interagente adicionar texto ao conteúdo replicado, o que pode, por isso, revelar outros regimes de interação que não a programação.

Já a parte destinada a comentários abre novas possibilidades e permite que o interlocutor se expresse. A maioria dessas manifestações pode ser classificada como pertencente ao regime de manipulação, já que representa respostas conectadas ao enunciado expresso pelo personagem fictício, ou seja, estão circunscritas às estratégias discursivas construídas pelo enunciador (no caso, o manipulador).

Considerando o texto da postagem atribuído ao personagem: "Que coisa BOA é a Academia da BOA hein! (Rimou kkk). Aqui a galera é $\mathrm{d}+$ e tá sempre ensinando, tem garçom novo e das antigas também! Vamos nessa que eu continuo na luta e aprendendo a ser um garçom melhor!”, julgamos incidirem no espectro do regime de manipulação os comentários do tipo: "Marcello continuem assim uma hora mau mau vai mudar e entrar de coração e alma na sua ele gosta falta pouco pra admitir bjs pra sua galera"; ou "Marcelao .... O ícone do \#quecoisaBoa rimou kkkkkkkkkk o que você fala vira versos para nos alegrar”; ou ainda "Pôr Marcelão conta outra e sem demagogia, desce a única BOA q vc conhece a ANTÁRTICA, desce agora”. Como se nota, são respostas que apenas ratificam o cerne do que foi primeiro enunciado e são a tônica de tudo que se lê em toda a área destinada à participação.

Todavia, em meio a tantas respostas reguladas, há de se considerar que é possível encontrar, mesmo que mais eventualmente, réplicas. Numa outra postagem da mesma página, é possível ver a seguinte manifestação: "Me responde ai que fiz uma aposta com um troxa que me disse que vcs era fake, pode me chingar kkkkk". Nesse caso, é notável que o interlocutor se comporta em desalinho com a discursividade presente no texto da postagem, forçando, com isso, um diálogo mais flexível, como os que caracterizam o regime de interação de ajustamento.

Mais raras ainda, contudo também observadas, são interpelações que contradizem as coerções feitas pelas postagens e trazem, dessa forma, instabilidade ao mecanismo de comunicação utilizado pela marca. Na postagem apontada na Figura 2, por exemplo, podemos identificar um comentário que diz: "Só mais a BRAHMA queridaaaaaaa", fala obviamente em contraposição com as perspectivas da manifestação da Antarctica e que, até por isso, pode se encaixar nas prerrogativas do regime de interação de acidente.

Como todos os comentários em postagens do Facebook podem ser moderados, ou seja, removidos e/ou bloqueados, não nos surpreende a marca manter aqueles que extrapolam a programação e a manipulação. Efetivamente, a ocorrência (e a notabilidade) das interações que se enquadram em regimes de ajustamento e de acidente confere legitimidade 
ao diálogo representado - talvez não em relação à marca, mas ao personagem fictício Marcelão da BOA; o que só ratifica nossa impressão de que os efeitos de sentido que confundem ficção e realidade são imperiosos para o sucesso da estratégia do branded content da Antarctica.

$\mathrm{E}$, se as marcas ficam de certa forma à mercê da postura assumida pelos seus prossumidores/coenunciadores, que, enfim, vão pontuar qual o regime de interação vai conduzir a relação estabelecida, por outro lado, o objetivo da marca só pode ser alcançado se os prossumidores escolhem justamente essa tal marca para coenunciar - e não outra.

\section{CONSIDERAÇÕES FINAIS}

Acerca do que analisamos, é substancialmente perceptível que o branded content, enquanto prática recente e tendente da comunicação de marcas na atualidade, apresenta novos recursos e mecanismos (e, com isso, novos contornos) que não só não foram contemplados pelos modos tradicionais do fazer publicitário, como requerem que a pesquisa contemporânea se esmere mais em desvendar seus aspectos próprios; e ainda, que o conceito de ciberpublicidade tem fôlego para ir muito mais longe do que já foi.

Particularmente, mesmo o artifício manifesto nos personagens fictícios, algo inédito enquanto fórmula de abordagem e manutenção do relacionamento com consumidores, apresenta uma variável enorme de nuances - tantas que nossas impressões nesse trabalho podem de fato ser consideradas apenas a ponta do iceberg do que tal prática pode ensejar em termos de compreensão das práticas ciberpublicitárias.

Ao final, aqui, resta-nos apenas sublinhar que a análise das interações travadas entre marcas, através de perfis fictícios, e prossumidores revelam que a interatividade em si continua se erigindo como paradigma fundamental para o desempenho da publicidade nos dias de hoje.

\section{REFERÊNCIAS}

ATEM, G. N.; OLIVEIRA, T. M.; AZEVEDO, S. T. (Orgs.). Ciberpublicidade: discurso, experiência e consumo na cultura transmidiática. Rio de Janeiro: E-papers, 2014.

COVALESKI, R. Idiossincrasias publicitárias. Curitiba: Maxi, 2013.

Conteúdo de marca e entretenimento: narrativas híbridas. Comunicação Mídia e Consumo, São Paulo, v. 12, n. 34, p. 107-123, maio/ago. 2015.

DONATON, S. Publicidade + entretenimento: por que estas duas indústrias precisam se unir para garantir a sobrevivência mútua. Tradução de Álvaro Oppermann. São Paulo: Cultrix, 2007.

EMOJI. Wikimedia Foundation, Flórida, 2018. Disponível em: <https://goo.gl/jWRH8h>. Acesso em: 27 jun. 2018.

FIGUEIREDO, C. Redação publicitária: sedução pela palavra. São Paulo: Pioneira Thompson Learning, 2005.

JENKINS, H. Cultura da convergência. Tradução Suzana Alexandria. 2. ed. São Paulo: Aleph, 2009.

LANDOWSKI, E. Interacciones arriesgadas. Lima: Fondo Editorial, 2009.

Entre comunicação e semiótica: a interação. Parágrafo, São Paulo, v. 4, n. 2, p. 207-217, 2016.

MARTí-PARREÑO, J.; RUIZ-MAFÉ, C.; SCRIBNER, L. (Eds.) Engaging consumers through branded entertainment and convergent media. Hersey: IGI Global, 2015.

PRIMO, A. A busca por fama na web: reputação e narcisismo na grande mídia, em blogs e no Twitter. In: CONGRESSO BRASILEIRO DE CIÊNCIAS DA COMUNICAÇÃO, 32., 2009,

Curitiba. Anais... São Paulo: Intercom, 2009. 